\title{
Morfología, parámetros micrográficos vegetativos, histoquímica y citogenética de Adesmia trijuga (Leguminosae, Papilionoideae) en el noroeste argentino
}

\author{
Morphology, vegetative micrographic parameters, histochemistry \\ and cytogenetics of Adesmia trijuga (Leguminosae, Papilionoideae) \\ in northwestern Argentina
}

Caro, María S. ${ }^{1,3}$; Ana I. Ruizz; Valeria de los A. Páez ; Patricia L. Albornoz ${ }^{2,3^{*}}$

1 Instituto de Genética; Fundación Miguel Lillo; Miguel Lillo 251; (T4000JFE) San Miguel de Tucumán, Argentina.

${ }^{2}$ Instituto de Morfología Vegetal; Fundación Miguel Lillo; Miguel Lillo 251; (T4000JFE) San Miguel de Tucumán, Argentina.

${ }^{3}$ Facultad de Ciencias Naturales e Instituto Miguel Lillo (U.N.T.). Miguel Lillo 205; (T4000JFE) San Miguel de Tucumán, Argentina.

ORCID:

Caro: https://orcid.org/0000-0002-0510-893X

Ruiz: https://orcid.org/0000-0002-0760-4582

Páez: https://orcid.org/0000-0002-3213-3890

Albornoz: https://orcid.org/0000-0001-7399-1982

* Autor corresponsal: plalbornoz@lillo.org.ar; albornoz@csnat.unt.edu.ar

\section{RESUMEN}

Adesmia trijuga es un arbusto espinoso, micrófilo, nativo, perenne; crece entre 1100$3000 \mathrm{~m}$ snm, en regiones montañosas de quebradas húmedas o zonas áridas y rocosas; vulgarmente es conocida como "cuerno de cabra", "añagua" o "suncho". A. trijuga es una especie polimórfica de hojas pinnadas con 3-5 pares de folíolos; con propiedades como forrajera, utilizada como leña y de amplia distribución en Argentina y Chile. Los antecedentes se refieren únicamente a la citogenética de poblaciones de la Región de Cuyo. El objetivo fue determinar los parámetros micrográficos vegetativos, histoquímicos y citogenética para caracterizar A. trijuga en poblaciones del noroeste argentino. Se recolectaron, al azar, cinco individuos en poblaciones ubicadas en

\footnotetext{
> Ref. bibliográfica: Caro, M. S.; Ruiz, A. I.; Páez, V. de los A.; Albornoz, P. L. 2020. “Morfología, parámetros micrográficos vegetativos, histoquímica y citogenética de Adesmia trijuga (Leguminosae, Papilionoideae) en el noroeste argentino". Lilloa 57 (2): 110-124. Fundación Miguel Lillo, Tucumán, Argentina. D.O.I.: doi. org/10.30550/j.lil/2020.57.2/3

> Recibido: 26 junio 2020 - Aceptado: 31 agosto 2020

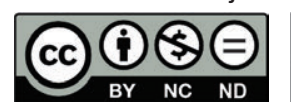

> URL de la revista: http://lilloa.lillo.org.ar

- Esta obra está bajo una Licencia Creative Commons Atribución - No Comercial - Sin Obra Derivada 4.0 Internacional.
} 
Jujuy, Salta y Tucumán. El material fue fijado en FAA y herborizado; se aplicaron técnicas anatómicas, histoquímicas y citogenéticas convencionales. Los resultados evidenciaron hojas paripinnadas, micrófilas, con folíolos de lámina entera, simétrica, obovada y venación pinnada-camptódroma-eucamptódroma. Folíolos anfistomáticos, pubescentes en ambas epidermis, con tricomas eglandulares y glandulares, los últimos de tres tipos; células epidérmicas isodiamétricas a rectangulares de paredes rectas a curvas con cutícula estriada; estomas anomocítico, hemibraquiparacítico, braquiparacítico, anfibraquiparacítico, hemianfibraquiparacítico y hemianficiclocítico; mesófilo equilateral; haces vasculares colaterales con casquete de esclerénquima hacia el floema y rodeados por vaina parenquimática. Pecíolo subcircular, con tricomas eglandulares y glandulares idénticos a los de la lámina foliolar; 2-3 estratos de clorénquima en empalizada subepidermico; 5 haces vasculares colaterales. Espinas de contorno circular, con crecimiento secundario, abundante esclerénquima y con tricomas idénticos a los de la lámina del folíolo y el pecíolo. Tubos e idioblastos con fenoles se presentan en el mesofilo de la hoja, médula del pecíolo y en la espina. El número cromosómico fue de $2 \mathrm{n}=20$ cromosomas. Los elementos de valor diagnóstico son: tipo de tricomas, cantidad y posición del tejido de sostén, idioblastos y tubos productores de fenoles y el número cromosómico.

Palabras clave - Adesmia; anatomía; citología; morfología.

\begin{abstract}
Adesmia trijuga is a thorny, microphyll, native and perennial shrub; growing between 1100-3000 $\mathrm{m}$ a.s.l. in mountainous regions of humid ravines or arid and rocky areas; it is commonly known as "cuerno de cabra", "añagua" or "suncho". A. trijuga is a polymorphic species with pinnate leaves with 3-5 pairs of leaflets with forage properties, used as firewood and widely distributed in Argentina and Chile. Background knowledge on the topic refers only to the cytogenetics of populations in the Cuyo Region. The objective of this work is to establish the vegetative, histochemical and cytogenetic micrographic parameters to characterize $A$. trijuga in populations of Northwestern Argentina. Five individuals were randomly collected from populations located in Jujuy, Salta and Tucumán. The material was fixed in FAA and herborized; traditional anatomical, histochemical and cytogenetic techniques were applied. The results evidenced paripinnateleaves, microphylls, with leaflets of entire leaf blade, symmetrical, obovate, and pinnate-camptodromous-eucamptodromous venation. Amphistomatic leaflets, pubescent in both epidermis, with eglandular and glandular trichomes the last being of three types; isodiametric to rectangular epidermal cells, with straight to curved walls with striated cuticle; anomocytic, hemibrachyparacytic, brachyparacytic, amphibrachyparacytic, hemi-amphibrachyparacytic, and hemiamphicyclocytic stomata; equilateral mesophyll; collateral vascular bundles with a sclerenchyma cap towards the phloem surrounded by parenchyma sheath. Petiole subcircular with eglandular and glandular trichomes identical to those of the foliolate lamina; 2-3 subepidermal layers of palisade chlorenchyma; five collat-
\end{abstract}


eral vascular bundles. Thorns circular in outline, with secondary growth, abundant sclerenchyma and with trichomes identical to those of the leaflet blade and petiole. Tubes and idioblasts containing phenolic substances are present in the mesophyll, in the petiole pith, and spines. The chromosome number was $2 n=20$. The elements of diagnostic value are the type of trichomes, the amount and position of mechanical tissue, phenol-producing idioblasts and tubes, and the chromosome number.

Keywords - Adesmia; anatomy; citology; morphology.

\section{INTRODUCCIÓN}

El género Adesmia DC. (Leguminosae, Papilionoideae) es exclusivamente sudamericano, su área de distribución se extiende desde el norte de Perú, a lo largo de la cordillera de los Andes, hasta Tierra del Fuego y hacia el este hasta las llanuras atlánticas, Mesopotamia y Brasil austral. Cuenta con alrededor de 240 especies herbáceas y arbustivas, y algunas en cojín de las regiones altoandinas, inermes y espinosas (Ragonese, 1969a, 1969b). El subgénero Acanthadesmia Burkart, caracterizado por plantas espinosas xeromórficas, está representado en Argentina por 6 series, con un total de 54 especies. En la serie Microphyllae, que comprende especies arbustivas, a veces bajas, pero sin llegar a formar cojines o placas, se encuentra Adesmia trijuga Gill. ex Hook. \& Arn. (Ulibarri, 1986). Adesmia trijuga es un arbusto espinoso, perenne, micrófilo, nativo de Argentina y Chile, crece entre 1100-3000 m snm en regiones montañosas de quebradas húmedas con pastizales o zonas áridas y rocosas; vulgarmente es conocida como "cuerno de cabra", "añagua" o "suncho" (Ulibarri, 1996; Ulibarri y Burkart, 2000). Es una especie polimórfica de hojas pinnadas con 3-5 pares de folíolos y frutos con emergencias pilosas. El epíteto específico deriva del número de folíolos, yugas o jugas, ya que generalmente la hoja presenta 3 pares (Burkart, 1962). En Argentina, A. trijuga tiene amplia distribución geográfica, encontrándose en las provincias de Catamarca, Chubut, Jujuy, La Pampa, La Rioja, Mendoza, Neuquén, Salta, San Juan, San Luis, Santa Cruz y Tucumán, donde se la considera una planta de interés económico dado que es empleada como forrajera (Cantero et al., 2019). En la provincia de Tucumán es una especie típica de la precordillera, se distribuye en la región prepuneña y pastizales altoandinos, aunque también hay registro de su presencia en Sierras de Medina (Noreste) (Caro, 2020). Según los criterios de la Unión Internacional para la Conservación de la Naturaleza (IUCN, 2020), el estado de conservación de $A$. trijuga es de preocupación menor. Al pertenecer a la familia Fabaceae, $A$. trijuga posee la capacidad de fijar nitrógeno, lo cual la convierte en una opción económica para mejorar la calidad de las pasturas en suelos de baja fertilidad; a su vez, con su porte arbustivo puede controlar la erosión del suelo (Coelho y Battistin, 1998; Thomas, 2000).

Solereder (1908) y Metcalfe y Chalk (1950), describen la anatomía foliar de las Fabaceae, Papilionoideae citando la presencia de papilas, células con taninos, proteínas o mucílago, epidermis con divisiones periclinales, tricomas glandulares y eglandulares y diferentes tipos de estomas y cristales. Metcalfe y Chalk (1950), des- 
criben la anatomía del pecíolo de las Papilionoideae estableciendo, de acuerdo con la organización vascular, dos grupos: haces separados o vascularización continua; citan células con proteínas, taninos o sustancias gomosas y cristales solitarios. Metcalfe y Chalk (1950), mencionan para el género Adesmia la presencia de células mucilaginosas en la epidermis foliar. Burkart (1964), Pykko (1966), Ragonese (1969a, 1969b), y Caro, Ruiz y Albornoz (2014, 2016) y Caro, Ruiz, Andrada y Albornoz (2018), describen caracteres morfológicos, anatómicos foliares y adaptaciones al ambiente xérico, en especies de Adesmia arbustivas y espinosas.

Desde el punto de vista citológico, los datos sobre el número cromosómico del subgénero Acanthadesmia son escasos, siendo el más frecuente $2 \mathrm{n}=2 \mathrm{x}=20$, con excepción de algunos tetraploides $2 \mathrm{n}=2 \mathrm{x}=40$ (Castronovo, 1945; Covas y Schnack, 1946; Covas, 1949; Krapovickas y Krapovickas, 1952; Rahn, 1960; Caro et al., 2016, 2018). Los antecedentes para $A$. trijuga son referidos a la citogenética de poblaciones de la Región de Cuyo en Argentina (Castronovo, 1945; Covas y Schnack, 1946; Covas, 1949).

Debido a los escasos antecedentes morfológicos, citogenéticos y a la escasa información referida a la anatomía, el objetivo de esta contribución fue caracterizar la morfología, parámetros micrográficos vegetativos, histoquímica y la citogenética de A. trijuga, en poblaciones del noroeste argentino (NOA).

\section{MATERIALES Y MÉTODOS}

\section{Material estudiado}

Se recolectaron al azar, ejemplares de Adesmia trijuga en poblaciones ubicadas en las provincias de Catamarca, Salta y Tucumán:

ARGENTINA. Prov. Tucumán, Dpto. Tafí del Valle, Loc. Infiernillo, 2642’282”S 65'47’972”O, 2842 m snm, 17-XII-2013, Caro 113 (LIL).

Prov. Tucumán, Dpto. Burruyacu, Sierra de Medina, 26²6’845"S 6502'573”O, 1236 m snm, 04-XI-2011, Caro 79 (LIL).

Prov. Salta, Dpto. Chicoana, Quebrada de Escoipe, 2511’038'S 6551'198”O, $3288 \mathrm{~m}$ snm, 21-XII-2010, Caro 70 (LIL).

Prov. Catamarca, Dpto. Santa María, Camino a Santa María, 27³7’799"S 6609'421"O, $1856 \mathrm{~m}$ snm, 14-XII-2011, Caro 86 (LIL).

\section{Análisis morfológico}

Los caracteres morfológicos vegetativos y reproductivos se analizaron a partir de material fresco; ellos fueron: hábito; presencia de espinas; forma de las estípulas; disposición de las hojas; número, longitud, ancho y tipo de borde de los folíolos; tipo de inflorescencia; color de la flor; longitud del lóbulo, del tubo del cáliz, de los estambres, de las anteras, del gineceo y de las semillas; longitud y ancho del estandarte y número de óvulos. 


\section{Análisis anatómico}

El estudio anatómico se realizó a partir de hojas, estípulas y espinas conservadas en FAA (formaldehido: ácido acético glacial: alcohol etílico 80\%, 1:1:8 v/v/v) (D'Ambrogio de Argüeso, 1986). Para el estudio de la epidermis y la arquitectura foliar se realizó la técnica de diafanización de Dizeo de Strittmatter (1973). La lámina foliolar, el pecíolo de la hoja y la espina fueron seccionados transversal y longitudinalmente según la técnica de "mano libre". Los cortes clarificados con hipoclorito de sodio al 50\% y lavados, fueron teñidos con cristal violeta o con la doble coloración de azul astra-safranina (D’Ambrogio de Argüeso, 1986; Zarlavsky, 2014). Los preparados temporarios se montaron en agua glicerina (1:1) y fueron sellados con esmalte para uñas. Los caracteres cuantitativos obtenidos fueron: densidad (estomas $/ \mathrm{mm}^{2}$ ), longitud y latitud $(\mu \mathrm{m})$ de estomas, con un $\mathrm{n}=10$ campos ópticos (objetivo $40 \mathrm{x}$ ) y cinco repeticiones por individuo (de un total de 10), para lo cual se tomó la parte media de la lámina.

La arquitectura foliar fue descripta según Hickey (1974) y Lindley (1951); mientras que, los tipos de estomas se describieron según la terminología propuesta por Dilcher (1974). En la caracterización anatómica se utilizó Fahn (1982) y en la morfología de estípulas a Weberling (2006).

\section{Análisis histoquímico}

El análisis histoquímico se realizó a partir de cortes transversales de lámina, pecíolo y espina, sobre los que se aplicaron pruebas de identificación y localización de almidón, compuestos fenólicos y sustancias lipofílicas con los reactivos Lugol, cloruro férrico y Sudán IV, respectivamente (D’Ambrogio de Argüeso, 1986).

\section{Análisis citológico}

El análisis citológico consistió en el recuento cromosómico a partir de meristemas de raíces jóvenes, pretratadas con 8 hidroxiquinoleina durante 24 horas a $4^{\circ} \mathrm{C}$, e hidrolizadas en $\mathrm{HCl} 1 \mathrm{~N} \mathrm{a} 60^{\circ} \mathrm{C}$ por 20 min y coloreadas con orceína acética al $2 \%$ (Guerra y de Souzat, 2002).

Las observaciones se efectuaron con microscopio estereoscópico (Olympus SZX7, Olympus Co., Tokyo, Japan) y microscopio óptico (Carl Zeiss, Axiostar Plus, Göttingen, Germany). Las fotomicrografías se obtuvieron con cámara digital (Canon A620, Power Shot 7,1MP y Olympus Sp-350 8MP). 


\section{RESULTADOS}

\section{Morfología}

Adesmia trijuga es un arbusto espinoso, laxo o enmarañado, de 0,3-2,0 m de alto, con ramas grisáceo-castañas; espinas simples o con 2-9 bifurcaciones delgadas que presentan abundantes espinas finas, blanquecinas o rojizas, ramificadas formando ramilletes con aspecto de abanico, o pseudoescorpioides, rara vez simples (Fig. 1A). Hojas paripinnadas, micrófilas de 6-20 mm de longitud, sin pelos o con pilosidad variable. Folíolos con número y tamaño variable de 3-5 pares con una longitud de 2,5-6,0 mm, obovados a elípticos-ovados, obtusos o emarginados (Fig. 1B). Las hojas y espinas presentan estípulas deltoides, rojizas, pilosas, de aproximadamente $1 \mathrm{~mm}$ de longitud a veces con pelos glandulosos en su margen (Fig. 1C). Las flores son amarillas con estrías rojizas, de 6-10 $\mathrm{mm}$ de longitud, sobre las espinas o en braquiblastos (Fig. 1D). Cáliz campanulado, piloso o piloso-glanduloso, con 5 lóbulos deltoides, generalmente más pequeños que el tubo (Fig. 1E); estandarte de 3-6 $\mathrm{mm}$ de longitud generalmente bien reflexo, glabro o piloso en el dorso, con un mechón de pelos en el centro de la uña recta (Fig. 1F), alas y quilla glabras (Fig. 1G, 1H). Estambres libres (10), en dos ciclos, de 7-8 $\mathrm{mm}$ de longitud, dos de los superiores geniculados, anteras uniformes (4-5 $\mathrm{mm}$ de longitud), dorsifijas (Fig. 1I). Gineceo (7-10 $\mathrm{mm}$ de longitud), con ovario lineal, pubescente y estilo largo, incurvo y glabro, estigma capitado (Fig. 1J). Fruto lomento con 2-5 artejos castaño-rojizos, cerdoso-pilosos. (Fig. 1K). Semilla lenticular, de aproximadamente $3 \mathrm{~mm}$ diámetro (Fig. 1L).

Arquitectura Foliolar. - Lámina del folíolo entera, simétrica, de forma obovada a elíptica-ovada, ápice redondeado, base obtusa-normal y margen entero (Fig. 2A). Pecíolo y peciólulo normales. Venación pinnada-camptódroma-eucamptódroma. Vena primaria de tamaño débil y recorrido derecho. Venas secundarias de grosor moderado, con ángulo de divergencia agudo-angosto y de recorrido derecho, con ramificaciones que forman ojales uniéndose a las secundarias superadyacentes en ángulo obtuso. Venas intersecundarias compuestas (Fig. 2A). Venas terciarias desarrollan un modelo reticulado al azar. Venación última marginal ojalada. Areolas con mallas incompletamente cerradas, dispuestas al azar, de forma poligonal, cuadrangular, sin vénulas o con vénulas simples, curvadas o lineares ramificadas una sola vez (Fig. 2B).

\section{Anatomía}

Lámina foliolar.- En vista paradermal, ambas epidermis presentan células isodiamétricas a rectangulares de paredes rectas a curvas y estomas, siendo las de la superficie abaxial las de menor tamaño (Fig. 2C, 2D). La cutícula es estriada. Los estomas son de tipo anomocítico, hemibraquiparacítico, braquiparacítico, anfibraquiparacítico, hemianfibraquiparacítico y anficiclocítico, con ciclo externo incompleto (Fig. 2E-F, 3A-C). Las células oclusivas poseen una longitud promedio de 19,89 


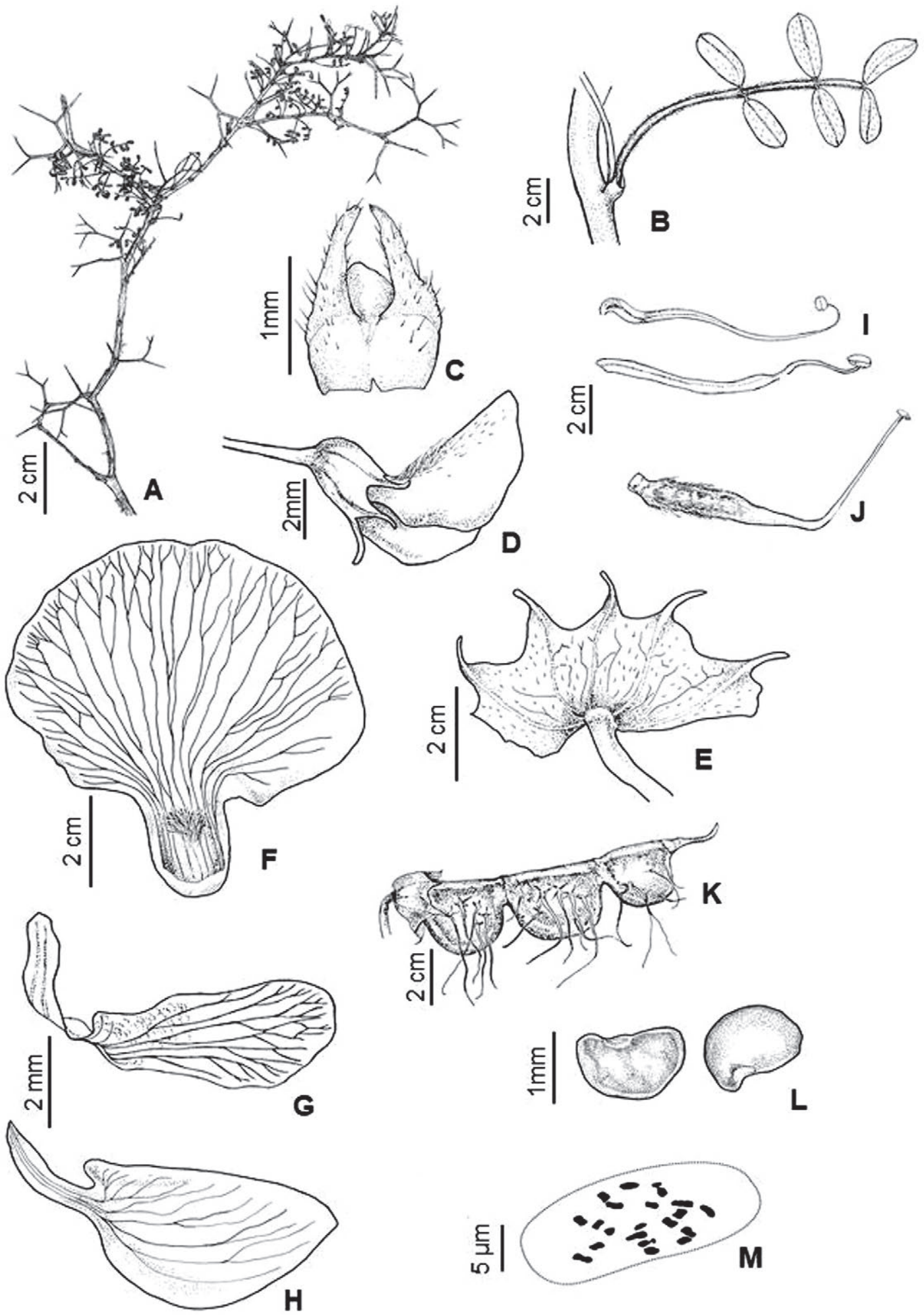

Fig. 1. Adesmia trijuga. Morfología. A) Aspecto general de la planta. B) Folíolos. C) Estípula. D) Flor. E) Cáliz. F) Estandarte. G) Ala. H) Quilla. I) Estambres. J) Gineceo. K) Fruto. L) Semilla. M) Número cromosómico $2 n=20$. Caro 113 (LIL).

Fig. 1. Adesmia trijuga. Morphology. A) General aspect of the plant. B) Leaflets. C) Stipule. D) Flower. E) Calyx. F) Vexillum. G) Wing. H) Keel. I) Stamens. J) Gynoecium. K) Fruit. L) Seed. M) Chromosome number $2 \mathrm{n}=20$. Caro 113 (LIL). 

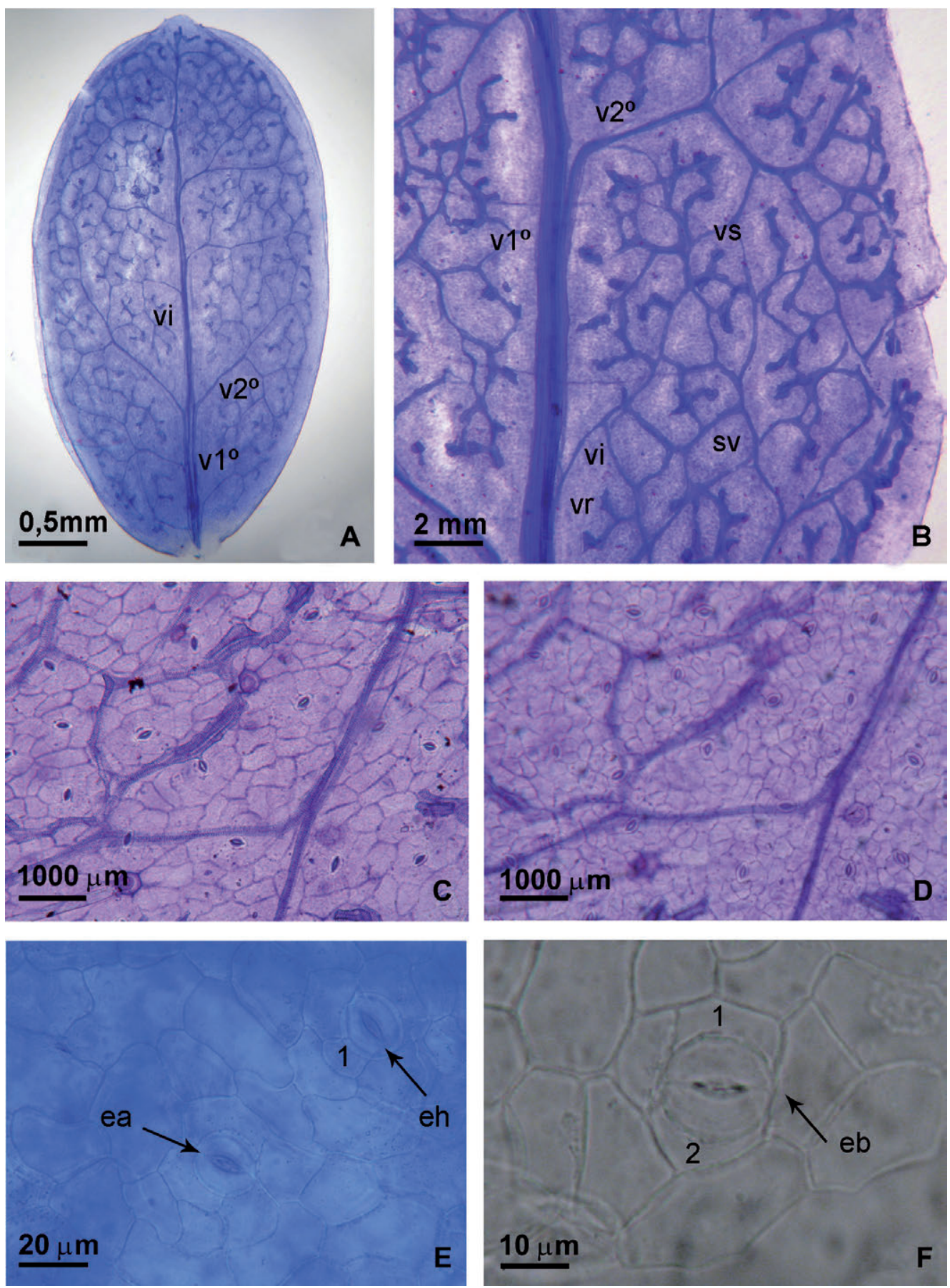

Fig. 2. Adesmia trijuga. A-B) Arquitectura foliolar. A) Venación. B) Areolas con mallas incompletamente cerradas, sin vénulas o con vénulas simples, curvadas o lineares ramificadas una sola vez. C-F) Anatomía de la lámina foliolar. C) Epidermis adaxial. D) Epidermis abaxial. E) Estomas, anomocítico y hemibraquiparacítico. F) Estoma braquiparacítico. Abreviaturas: ea: estoma anomocítico; eb: estoma braquiparacítico; eh: estoma hemibraquiparacítico; vi: vena intersecundaria; v1 ${ }^{\circ}$ : vena primaria; $\mathrm{v}^{\circ}$ : vena secundaria; sv: sin vénula; vr: vénula ramificada; vs: vénula simple; 1,2 : células subsidiarias. Caro 79, 113 (LIL).

Fig. 2. Adesmia trijuga. A-B) Leaflet architecture. A) Venation. B) Areoles with incompletely closed meshes, without venules or venation simple, curved or linear venules branched once. C-F) Leaflet anatomy. C) Upper epidermis. D) Down epidermis. E) Stomata, anomocytic and hemibrachyparacytic. F) Stoma brachyparacytic. Abbreviations: ea: anomocytic stoma; eb: brachyparacytic stoma; eh: hemibrachyparacytic stoma; vi: intersecundary vein; $1^{\circ}$ : primary vein; $2^{\circ}$ : secondary vein; sv: without venule; vr: branched venule; vs: simple venula; 1, 2: subsidiary cells. Caro 79, 113 (LIL). 
$\mu \mathrm{m}( \pm 0,16)$ y una latitud promedio de $13,98 \mu \mathrm{m}( \pm 0,14)$. La densidad estomática promedio es de 94,5 estomas $/ \mathrm{mm}^{2}$ en la epidermis adaxial y de 150,8 estomas $/ \mathrm{mm}^{2}$ en la epidermis abaxial. Se observan tricomas eglandulares y glandulares en ambas superficies epidérmicas. Los primeros son tricelulares, uniseriados, adpresos, la célula de inserción a la epidermis es redondeada, la célula central es corta y rectangular, mientras que la célula terminal es larga de extremo aguzado, pared gruesa y cutícula estriada, las células epidérmicas se disponen radialmente en la base de estos tricomas (Fig. 3D). Los tricomas glandulares son de tres tipos: a) pluricelular, biseriado en la porción basal, con una glándula en el extremo distal (Fig. 3E), b) pie y cabeza unicelulares, la célula del pie es corta, rectangular de paredes gruesas y la cabeza es globosa (Fig. 3F), c) pluricelular, de base pluriseriada ensanchada, desde la porción media hacia el extremo es biseriado, con una glándula terminal que se desprende con facilidad (Fig. 3G). Los tricomas eglandulares son los más numerosos, los glandulares de tipo "c" son los más escasos.

En corte transversal el contorno de la lámina es plano, con una tenue concavidad adaxial a la altura de la vena primaria (Fig. $3 \mathrm{H}$ ). El mesofilo es equilateral, con parénquima adaxial y abaxial formados, cada uno, por 3 estratos compactos de células, y el parénquima paravenal se observa entre las venas contiguas (Fig. 3I). Los haces vasculares son colaterales con esclerénquima hacia el floema y rodeados por la vaina parenquimática (Fig. 3H, 3I).

Pecíolo.— En vista superficial ambas epidermis, subglabras, poseen células rectangulares a cuadrangulares con paredes rectas, gruesas y cutícula ornamentada, con estomas y tricomas eglandulares y glandulares idénticos a los descriptos para la lámina (Fig. 3J). En corte transversal es subcircular con la cara adaxial cóncava (Fig. $3 \mathrm{~K})$. La epidermis es unistrata, con la pared periclinal externa engrosada y cutícula gruesa. Internamente, el clorénquima está formado por 2-3 estratos en empalizada. El tejido vascular está organizado en 5 haces vasculares colaterales, inmersos en el parénquima; ubicándose los tres de mayor tamaño en posición central, todos presentan casquetes de esclerénquima que se observan hacia el floema (Fig. 3L).

Espina caulinar.- En vista superficial la epidermis presenta células rectangulares a isodiamétricas de paredes rectas a curvas, cutícula gruesa, ornamentada. Los estomas y tricomas son idénticos a los descriptos para la lámina del folíolo, observándose además el tipo anfibraquiparacíticos con tres pares de células subsidiarias (Fig. 3M). Predominan los tricomas glandulares con base pluricelular ensanchada. En corte transversal es circular con crecimiento secundario temprano (Fig. 4A). La epidermis unistrata está formada por células de paredes y cutícula, gruesas. En posición subepidérmica se observa un estrato de células colenquimáticas; continúan tres estratos de células en empalizada, y el último estrato de la corteza está formado por conductos articulados con fenoles. Los tejidos de conducción, floema y xilema, se presentan continuos por la actividad del cámbium, formando una estela de tipo protostela. Asociado al floema se presenta esclerénquima discontinuo, formado por fibras. En el centro se observa la médula lignificada. (Fig. 4A). 

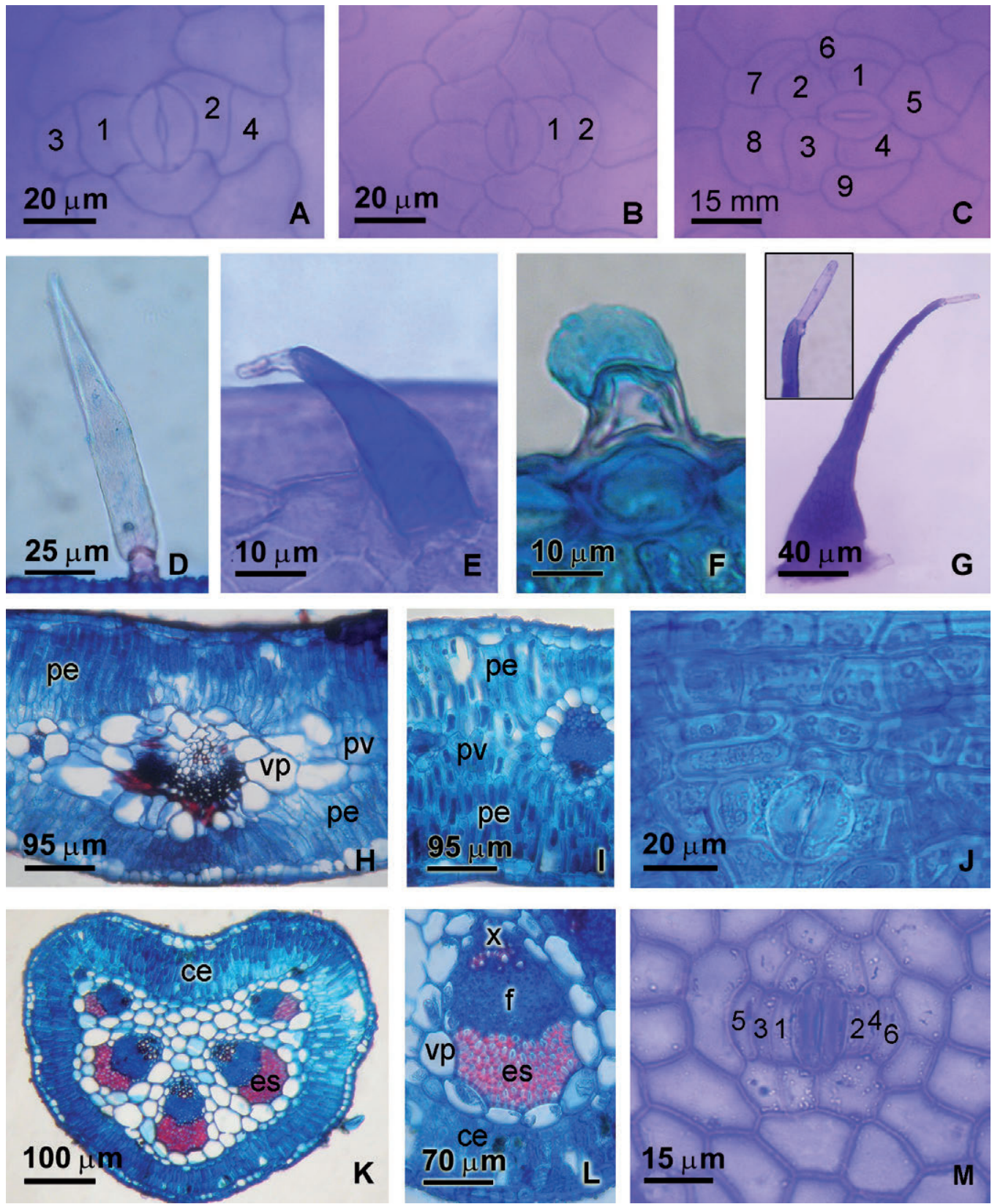

Fig. 3. Adesmia trijuga. Anatomía de la lámina foliolar. A-C) Estomas. A) Anfibraquiparacítico. B) Hemianfibraquiparacítico. C) Anficiclocítico, con ciclo externo incompleto. D) Tricoma eglandular. E-G) Tricomas glandulares. E) Tipo a. F) Tipo b. G) Tipo c, en imagen incluida se observa el detalle de la glándula. H) Corte transversal a la altura de la vena primaria. I) Detalle del mesofilo equilateral. J-L) Anatomía del pecíolo. J) Epidermis con estoma braquiparacítico. K) Corte transversal. L) Detalle de un haz vascular. M) Epidermis de la espina caulinar con estoma anfibraquiparacíticos con tres pares de células subsidiarias. Abreviaturas: 1-9: células subsidiarias; ce: clorénquima en empalizada; es: esclerénquima; f: floema; pe: parénquima en empalizada; pv: parénquima paravenal; vp: vaina parenquimática; x: xilema. Caro 79, 113 (LIL).

Fig. 3. Adesmia trijuga. Leaf blade anatomy. A-C) Stomata. A) Amphybrachyparacytic. B) Hemiamphybrachyparacytic. C) Amphycyclocytic, with incomplete external cycle. D) Eglandular trichome. E-G) Glandular trichomes. E) Type a. F) Type b. G) Type c, in included image shows the gland detail. H) Cross section at level of the primary vein. I) Detail of the equilateral mesophyll. J-L) Petiole anatomy. J) Epidermis with brachyparacytic stoma. K) Cross section. L) Vascular bundle detail. M) Epidermis of the caulinar thorn with amphibrachyparacytic stoma with three pairs of subsidiary cells. Abbreviations: 1-9: subsidiary cells; ce: palisade chlorenchyma; es: sclerenchyma; f: phloem; pe: palisade parenchyma; pv: Paravenal parenchyma; vp: parenchyma sheath; x: xylem. Caro 79, 113 (LIL). 
Análisis Histoquímico.- Las pruebas histoquímicas resultaron negativas para almidón.

Los lípidos fueron revelados en la cutícula de todas las estructuras analizadas (Fig. 4B, 4C), en las células parenquimáticas del mesofilo foliolar, del córtex y de la médula de la espina como cuerpo oleífero (Fig. 4D), y en la célula corta del tricoma eglandular (Fig. 4E).

Los compuestos fenólicos se evidenciaron en conductos articulados e idioblastos; los primeros se ubican próximos a los haces vasculares de la lámina (Fig. 4F, $4 \mathrm{G}$ ) y en la médula del pecíolo (Fig. $4 \mathrm{H}$ ) de ejemplares de poblaciones de alto nivel altitudinal (3288 m snm), mientras que en la espina constituyen el último estrato del córtex (Fig. 4I). Los idioblastos fenólicos se observan en posición subepidérmica del pecíolo (Fig. 4J), en ejemplares recolectados en poblaciones de bajo nivel altitudinal (1856 m snm).

Análisis Citológico.- El número cromosómico obtenido para la especie estudiada fue de $2 \mathrm{n}=20$, con cromosomas pequeños, cuyas longitudes varían de $1-2 \mu \mathrm{m}$ (Fig. $1 \mathrm{M})$.

\section{DISCUSIÓN}

La presente contribución describe por primera vez los parámetros micrográficos vegetativos, histoquímica y número cromosómico de Adesmia trijuga en poblaciones del noroeste argentino. A. trijuga es una especie endémica típica de regiones montañosas del NOA. En la provincia de Tucumán se distribuye en la región prepuneña y pastizales alto andino, aunque Caro (2020) registró su presencia en Sierras de Medina (Noreste), ampliando así su área de distribución. La abundancia de las poblaciones naturales, sumado a su amplia distribución, confirma la categoría de preocupación menor otorgada por la UICN. Caro (2020) menciona que esta especie presenta hojas que persisten todo el año, la floración se produce de octubre a abril, y la fructificación de noviembre a mayo.

Las investigaciones morfológicas y reproductivas realizadas en este trabajo corroboran el polimorfismo morfovegetativo y reproductivo mencionado por otros autores. Presenta caracteres morfológicos que se corresponden a ambientes xéricos, sin embargo, en el NOA en lugares sombríos y húmedos presentan foliolos más anchos, alargamiento de las ramas y pocas espinas (Ulibarri, 1986, Caro, 2020). Las variables referidas a la alta pubescencia, reducción de los folíolos, presencia de espinas caulinares con abundante esclerénquima, folíolo anfistomático, mesofilo equilateral de parénquima compacto y la presencia de fenoles ponen en evidencia caracteres propios de plantas xeromórficas, lo cual demuestra una estrecha relación morfológica, histológica e histoquímica con el hábitat donde fue recolectada la especie.

En relación con la anatomía, Solereder (1908) y Metcalfe y Chalk (1950), citan para las Fabaceae-Papilionoideae la presencia de diferentes tipos de estomas, células tánicas y tricomas eglandulares/glandulares. A. trijuga evidenció las mismas estructuras descriptas por estos autores. Los tipos de estomas encontrados fueron anomo- 

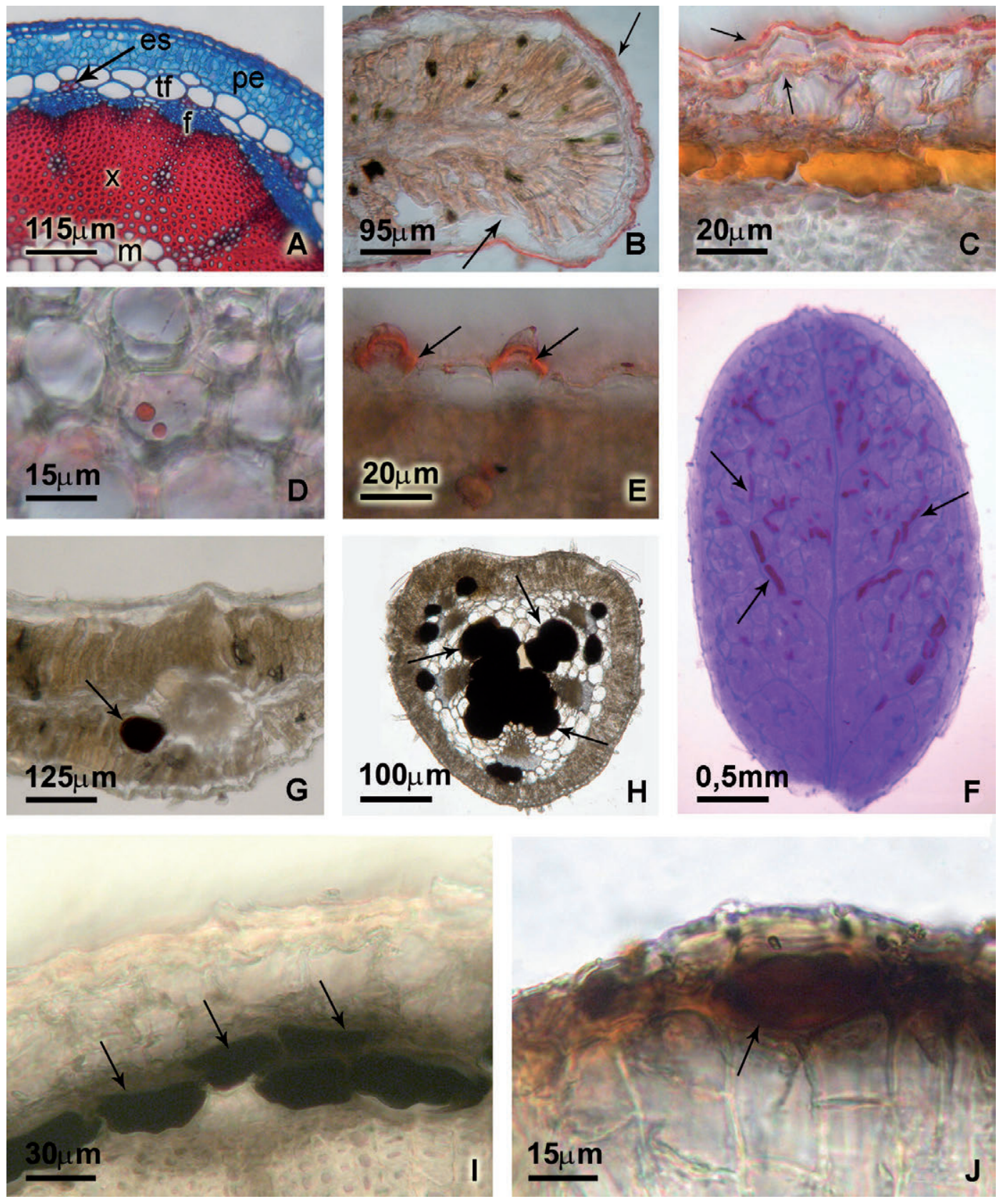

Fig. 4. Adesmia trijuga. A) Corte transversal de la espina. B-J) Histoquímica. B-E) Tinción con Sudán IV (lípidos). F-J) Tinción con cloruro férrico (compuestos fenólicos). B) Cutícula foliolar. C) Cutícula de la espina. D) Cuerpos oleíferos. E) Paredes de la célula corta del tricoma eglandular. F-I) Conductos articulados con fenoles. F) En vista paradermal del folíolo se observan próximos a la venación. G) En corte transversal del folíolo, en la vaina del haz vascular. H) En corte transversal del pecíolo, en la médula. I) En corte transversal de la espina, próximo a la vascularización. J) Idioblastos subepidérmicos con fenoles en el pecíolo. Abreviaturas: es: esclerénquima; f: floema; m: médula; pe: parénquima en empalizada; tf: tubo fenólico; x: xilema. Caro 70, 86 (LIL).

Fig. 4. Adesmia trijuga. A) Cross section of the thorn. B-J) Histochemistry. B-E) Test for lipophilic substances with Sudan IV. F-J) Test to identified phenolic compounds with ferric chloride. B) Foliolar cuticle. C) Cuticle of the thorn. D) Oil bodies. E) Short-cell walls of the eglandular trichome. F-I) Articulated conduits with phenols. F) In paradermal view of the leaflet they are seen close to the venation. G) In cross section of the leaflet, in the vascular bundle sheath. $H$ ) In cross section of the petiole, in the medulla. I) In cross section of the spine, close to vascularization. J) Subepidermal idioblasts with phenols in the petiole. Abbreviations: es: sclerenchyma; f: phloem; m: pith; pe: palisade parenchyma; tf: phenolic tube; x: xylem. Caro 70, 86 (LIL). 
cítico, hemibraquiparacítico, braquiparacítico, anfibraquiparacítico, hemianfibraquiparacítico y hemianficiclocítico en la lámina foliolar, además anfibraquiparacíticos con tres pares de células subsidiarias en la espina; conductos articulados e idioblastos con fenoles se encuentran en lámina foliolar, pecíolo y espina; los tricomas son de tipo eglandular y glandular. Metcalfe y Chalk (1950) citan para el género Adesmia la presencia de células mucilaginosas en la epidermis foliolar, las cuales no fueron registradas en la especie estudiada. Estos autores, en cuanto a la vascularización del pecíolo, establecen dos grupos: haces separados o vascularización continua; $A$. trijuga presentó 5 haces vasculares colaterales dispuestos en arco.

Adesmia trijuga reveló hojas con estomas en ambas epidermis. Algunos autores señalan el carácter anfistomático como un evento común en plantas que crecen en ambientes con intensa radiación solar (Mott \& Michaelson, 1991), tal vez debido a que ésta es una adaptación para incrementar la tasa fotosintética (Gibson, 1996).

Los resultados referidos a una mayor densidad estomática en la superficie abaxial en $A$. trijuga, coinciden con Martín y Glover (2007) quienes refieren que, generalmente la densidad es mayor en la superficie abaxial, lo cual puede prevenir pérdida de agua al estar menos expuesta al calentamiento. El número de estomas en las diferentes especies vegetales es variable; $A$. trijuga presentó una densidad total (adaxial más abaxial) de 245 estomas $/ \mathrm{mm}^{2}$, que según Leegood (1993) para plantas C3, corresponde a una densidad alta propia de plantas de ambientes xéricos como es la especie en estudio.

Los resultados citogenéticos constituyen un nuevo aporte para la serie Microphylla y son inéditos para $A$. trijuga del NOA. Es una especie diploide $2 \mathrm{n}=2 \mathrm{x}=20$, con cromosomas pequeños, y coincide con el numero cromosómico registrado por Covas (1949) y con la mayoría de los números cromosómicos registrados para las especies del subgénero Acanthadesmia (Castronovo, 1945; Covas y Schnack, 1946; Covas, 1949; Krapovickas y Krapovickas, 1952; Rahn, 1960; Caro et al., 2016, 2018).

\section{CONCLUSIONES}

Los caracteres de valor diagnóstico para la identificación de $A$. trijuga son: tamaño y color de la flor, número de folíolos por braquiblasto, cutícula estriada, tipos de estomas y tricomas, densidad estomática, cantidad y posición del tejido de sostén, número cromosómico, idioblastos y conductos articulados productores de fenoles. Estos resultados aportan nuevos rasgos que contribuirán a la taxonomía e identificación rápida y precisa de este polimórfico taxón.

\section{AGRADECIMIENTOS}

Esta investigación se enmarca en los proyectos B-0013-1 y B-0002-1 (Miguel Lillo 251, T4000JFE, Tucumán). Agradecemos a la Fundación Miguel Lillo por el espacio físico y el equipamiento que permitió la realización de este estudio. A la Lic. Lelia Bordón de la sección Iconografía (FML), por la realización de las láminas, y al Lic. 
Aldo R. Andrada, del Instituto de Genética (FML), por su colaboración en los viajes de colección.

\section{BIBLIOGRAFÍA}

Burkart, A. (1962). Contribución al estudio del género Adesmia (Leguminosae), IV. Darwiniana 12 (3): 309-364.

Burkart, A. (1964). Contribución al estudio del género Adesmia (Leguminosae), V. Darwiniana 13 (1): 9-66.

Cantero, J., Núñez, C., Bernardello, G., Amuchástegui, A., Mulko, J., Brandolin, P., Palchetti, V., Iparraguirre, J., Virginil, N. y Ariza Espinar, L. (2019). Las Plantas de interés económico en Argentina. Río Cuarto, Argentina, UniRío editora.

Caro, M. S. (2020). Adesmia trijuga. Cuerno de cabra. Universo Tucumano 46: 1-12.

Caro, M. S., Ruiz, A. I. y Albornoz, P. L. (2014). Morfología, anatomía foliar y aporte citológico de Adesmia cordobensis var. cordobensis (Fabaceae) del Noroeste argentino. Lilloa 51 (2): 141-150.

Caro, M. S., Ruiz, A. I., y Albornoz, P. L. (2016). Exomorfología, anatomía vegetativa y citología de Adesmia schickendanzii (Fabaceae-Papilionoideae) del Noroeste argentino. Lilloa 53 (1): 3-11.

Caro, M. S., Ruiz, A. I., Andrada, A. R., Albornoz, P. L. (2018). Morfología vegetativa y floral, anatomía foliar y de la espina caulinar y primeros recuentos cromosómicos de Adesmia cytisoides y Adesmia inflexa (Fabaceae, Papilionoideae) del Noroeste Argentino. Lilloa 55 (2): 17-29. doi: https://doi.org/10.30550/j.lil/2018.55.2/3

Castronovo, A. (1945). Estudio cariológico de doce especies de Leguminosas argentinas. Darwiniana 7 (1): 38-57.

Coelho, L. y Battistin, A. (1998). Meiotic behavior of Adesmia DC (Leguminosae, Faboideae) species native to Rio Grande do Sul, Brazil. Short Communication. Genética Molecular Biológica 21: 404-406. https://doi.org/10.1590/S141547571998000300020

Covas, G. (1949). Estudios cariológicos en Antófitas. III parte. Darwiniana 9 (1): 158-162.

Covas, G. y Schnack, B. (1946). Número de cromossomos en antófitas de la región de Cuyo (República Argentina). Revista Argentina de Agronomía 13 (3): 153-166.

D’Ambrogio de Argüeso, A. (1986). Manual de Técnicas en Histología Vegetal. Editorial Hemisferio Sur S. A., Buenos Aires, 83 pp.

Dilcher, D. L. (1974). Approaches to the identification of angiosperm leaves. The Botanical Review 40: 1-157.

Dizeo de Strittmatter, C. G. (1973). Nueva técnica de diafanización. Boletín de la Sociedad Argentina de Botánica 15: 126-129.

Fahn, A. (1982). Anatomía Vegetal. Editorial Pirámide. Madrid, 599 pp.

Gibson, A. (1996). Structure-function relations of warm desert plants. Springer, Berlín.

Guerra, M; de Souza M. J. (2002) Como observar cromossomos: Um Guia de Técnicas em Citogenética Vegetal, Animal e Humana. Ribeirão Preto, SP: Fundação de Pesquisas Científicas de Ribeirão Preto. Ed. FUNPEC. 131pp. 
Hickey, L. J. (1974). Clasificación de la arquitectura de las hojas de Dicotiledóneas. Boletín de la Sociedad Argentina de Botánica 16 (1-2): 1-26.

IUCN (2020). The IUCN red list of threatened species .Versión 2. Recuperado de http://www.iucnredlist.org.

Krapovickas, A. y Krapovickas, A. M. F. (1952). Notas citológicas sobre leguminosas. Darwiniana 9 (3-4): 612-613.

Leegood, R. C. (1993). Carbon dioxide concentrating mechanisms. In: Plant Biochemistry and Molecular Biology (Eds. P.J. Lea and R.C. Leegood), pp. 47-72, John Wiley and Sons, New York.

Lindley, J. (1951). Glosología de los términos usados en Botánica. Fundación Miguel Lillo. Miscelanea 15: 1-23.

Martin, C. y Glover, B. (2007). Aspectos funcionales del patrón celular en la epidermis aérea. Current Opinion in Plant Biology 10: 70-82.

Metcalfe, C. R. y Chalk, L. C. (1950). Anatomy of the Dicotyledons. Clarendon Press, Oxford.

Mott, K. y Michaelson, O. (1991). Amphistomy as an adaptation to high light intensity in Ambrosia cordifolia (Compositae). American Fournal of Botany 78: 76-79.

Pykko, M. (1966). The leaf anatomy of East Patagoniac xeromorphic plants. Annales Botanici Fenici 3 (4): 453-622.

Ragonese, A. M. (1969a). Vascularización de la base foliar y pecíolo de algunas especies de Adesmia. Darwiniana 15 (1-2): 143-149.

Ragonese, A. M. (1969b). Anatomía del género Adesmia (Leguminosas). Darwiniana $15(1 / 2): 150-182$.

Rahn, K. (1960). Chromosome numbers in some South American Angiosperms. Botanisk Tidsskrift 56 (2): 117-127.

Solereder, H. (1908). Systematic anatomy of the Dicotyledons. Oxford at the Clarendon Press, London.

Thomas, R. (2000). Nitrogen fixation by forage legumes as a driving force behind the recuperation and improvement of soil quality in tropical agricultural systems: opportunities for wider use of forage legumes? En Pedrosa F, Hungria M, Yates MG, Newton WE (Coords.) Nitrogen Fixation: From Molecules to Crop Productivity. Kluwer. Dordrecht, Holanda. pp. 539-540.

Ulibarri, E. A. (1986). Especies de Adesmia de la serie Microphyllae (LeguminosaePapilionoideae). Darwiniana 27 (1-4): 315-388.

Ulibarri, E. A. (1996). Fabaceae Lindley Tribu 10. Adesmiae (Benth.) Hutchinson. Flora del Valle de Lerma. Aportes Botánicos de Salta (Argentina). Serie Flora 4 (8): 1-11.

Ulibarri, E. A. y Burkart, A. (2000). Sinopsis de las especies de Adesmia de la Argentina. Darwiniana, nueva serie 38 (1-2): 59-126. doi: https://doi.org/10.14522/ darwiniana.2014.381-2.162

Weberling, F. (2006). Las estípulas como caracteres sistemáticos confiables. Boletín de la Sociedad Argentina de Botánica 41 (1-2): 127-150.

Zarlavsky, G. E. (2014). Histología vegetal: Técnicas simples y complejas. Sociedad Argentina de Botánica. Buenos Aires, Argentina, 198 pp. 